\title{
Comparative efficacy of Neem leaves and Ivermectin (Ivomec $®$ ) against ectoparasites in calves
}

\author{
M. M. Rahman, M. Mostofa, M. S. Jahan and M. A. H. M. Kamal \\ Department of Pharmacology, Bangladesh Agricultural University, Mymensingh-2202, Bangladesh
}

\begin{abstract}
The experiment was carried out for 28 days from August to September 2007 to investigate the efficacy of Ivermectin and Neem plants against ectoparasites in calves. Effect of Ivermectin and Neem plants on certain blood parameters hemoglobin ( $\mathrm{Hb}$ ), packed cell volume (PCV), total leukocyte count (TEC) and erythrocyte sedimentation rate (ESR) were studied in calves. A total of 15 calves were examined for the presence of ticks by physical examination and were divided into three equal groups as, Group A (infected control group), Group B (treated with Neem) and Group C (treated with Ivermectin). The therapeutic efficacy of Ivermectin was $100 \%$ against ectoparasites in calves on day 7, 14, 21 and 28 after the treatment of Ivermectin. Ivermectin and Neem showed significant effectiveness at $7 \mathrm{th}, 14 \mathrm{th}, 21^{\text {st }}$ and 28 th day of post treatment. The effects on TEC, Hb level was increased significantly at 7th, 14th and 28th day of treatment and PCV level was increased significantly on 28th day of treatment. On the other hand indigenous medicinal plant Neem leaves shown the efficacy of $68 \%$ at day 28 and body weight of Ivermectin and Neem treated calves also increased. All the calves after Ivermectin injection and Neem spray remained healthy, no adverse effect and calves appetite increased, growth and coat color improved rapidly.
\end{abstract}

Keywords: Ivermectin, Neem, Ectoparasites, and Haemoglobin

\section{Introduction}

Ectoparasites in livestock are very common in Bangladesh. The ectoparasites entirely live on blood and lymph of all kinds of vertebrate animal. The damages caused by ticks are irritation, inflammation, exudation of lymph which coagulates to form crusts. Ectoparasites, like ticks, play an important role as vector of deadly pathogens to animals and man. Mites cause dermatitis, alopecia and sometimes animals are infected secondarily by bacteria causing toxemia, septicemia and ultimately dead of the animals.

Most of the farmers in Bangladesh cannot afford to buy modern medicine for the treatment of the livestock because of high price of the drug and poor economic condition of the farmers. So, if we can develop the traditional system of medicine in Bangladesh it will be highly beneficial for the farmers and for the overall improvement of the livestock. Recently much interest in the field of medicinal plants has been grown throughout the world. Many countries have already come to realize the medicinal plants as a potential means of therapeutic agent and also their availability and cost effectiveness. Various kinds of herbal extract showed the Larvicidal and Acaricidal effects as reported by (Chungsamarnyart, and Jansawan, 1991).

In developed countries the principles of controlling helminth parasites (Ecto) are based on pasture, barn management and protective treatments but in Bangladesh where animals are mainly maintained in mixed farming system with virtually no pasture land for grazing, these methods have limitation to control parasites. So, protective treatments with routine dosing of anthelmintics and dipping with ectopesticides would be the choice of controlling the parasites in animals of Bangladesh. The present research is being conducted to study the efficacy of medicinal plant in veterinary practice. In Bangladesh many drugs are being used for long time to combat parasitic infection in livestock. A large number of anthelmintics are now available in the market. The indiscriminate use of anthelmintics made the parasites to be resistant against the drug, which have been reported by experts throughout the world including Bangladesh (Hannan, et al., 2001). So, we should have to back the traditional uses of me declines.

The Agro-ecological and geo-climatic condition of Bangladesh favors the survival, multiplication, spread and perpetuation of animal parasites. Moreover animal management and managerial system play an important role in high degree of occurrence of parasitic disease in Bangladesh. There are several indigenous medicinal plants (Nath, et al., 1983; Mostofa, 1983) have anthelmintics action and used against both ecto and enodparasites in Bangladesh (Mostofa, 1983; Mannan, et al., 1997) India (Dutta and Hazarika, 1976). There are various types of ivermectin which are imported from abroad 
and very costly, having side effects and they are not equally active on all stages of lifecycle of ectoparasites. Ivermectin stimulates the release of GABA from nerve ending and enhance binding of GABA to special receptors at nerve junctions.

Ivermectin subcutaneous infection preparation is easy to administration to the calf without any risk that is associated with any other routes of administration. Ivermectin was safest and more effective for the treatment of endo and ectoparasites. The chemicals used against ectoparasites are hazardous for both man and animals. Our poor farmers are illiterate they can not apply insecticides on the animal body properly. In addition, there is no report on the toxic and residual effect of ivermectin injectable formulation. As far as we know no research paper is available on the efficiency of ivermectin $(\mathrm{S} / \mathrm{C})$ on calves in Bangladesh. Therefore, the patent drug Ivomec (Ivermectin) and locally available medicinal plant (Neem) was selected with the aim to for comparative investigation of the efficacy of anthelmentic activity on ectoparasites and on some hematological parameters in calves. The present study also paid attention to study the adverse effect of the both treatment

\section{Materials and Methods}

The experiment was carried-out for a period of 6 months from June to November, 2007 in the Department of Pharmacology and Department of Physiology of Bangladesh Agricultural University Mymensingh. Fifteen calves of both sexes aged between 5 to 6 months were primarily selected in this study. All the calves were examined for the presence of ectoparasites and the efficacy of Ivermectin and indigenous medicinal plant (Neem) were studied against these naturally infested ectoparasites. The calves were divided into 3 equal groups (Group A, B and C). Calves of group A was kept as infected control. Rest 2 groups i.e. B and C were treated with Neem spray and Ivermectin, respectively.

Neem leaves were collected from BAU campus and made $15 \%$ solution for spray of the selected animals. Saturated salt solution, Normal saline (0.9\%), anticoagulant sodium citrate $(3.8 \%)$ Hayem's solution, (0.14\%) Hydrochloric acid solutions were prepared following the standard procedurees. Render neem collection from Botanical garden, BAU. The leaves were dried and powdered. $15 \mathrm{gm}$ of leaf powder was mixed with $100 \mathrm{ml}$ distilled water and stirred for $2 \mathrm{hr}$. It was kept overnight at 40C and the supernatant was collected. This was used as the crude leaf extract to study. The ectoparasites (ticks) was detected by physical examination of the animals and the presence of ectoparasites were recorded. Ticks infestation was examined physically on individual animal. The procedure of examination was to count the adult ticks of Para lumber region with an area of $6 \times 5$ i.e. 30 square cm. The selected 30 square $\mathrm{cm}$ were marked with a permanent colour and ticks within this area were counted at pretreatment and post treatment days. Group-A was considered as control group (no drugs

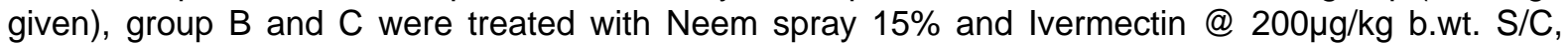
respectively. After injection of Ivermectin and application of Neem all the calves (three groups) with one control group were closely observed for 28 days of post treatment and the considered parameters were (a) Clinical parameters (severity of infestation, feeding efficiency, conditions of hair coat, body weight and adverse effects). (b) Hematological parameters (TEC, Hb, PCV and ESR). All the calves were allowed for free pasture grazing for 2-3 hours daily. Adequate plenty of water was also provided to all calves.

The severity of infestation of ectoparasites (ticks) was observed by counting the number of ectoparasites in a selected area of the individual calves. The ectoparasites were detected by visual examination of the calves and the number of parasites was recorded. The ticks within this area were counted at pre-treatment at day 0 and at $7^{\text {th }}, 14^{\text {th }}, 21^{\text {st }}, 28^{\text {th }}$ day treatment period. Body weight was observed accordingly before treatment (day ' 0 ') and 28 days of treatment. The adverse effects (if any) of the treated calves were also examined before and after treatment as per above mentioned schedule i.e. 7th, 14th, 21st and 28th day treatment. Hair coat of the treated calves as well as the untreated infected control group was physically examined by visual examination before and after treatment. Feeding efficiency of treated and untreated (infected control) groups was compared at pretreatment (0 day), treatment (7th, 14th, 21st and 28th) period. 
Blood samples were collected from Jugular vein of the calves of treated and control group in vials containing anticoagulant (Sodium Citrate 3.8\%) at day 0, 7th, 14th and 28th of treatment period to determine the effects of ivermectin and neem on the following hematological parameters such as Total Erythrocyte Count (TEC), Hemoglobin ( $\mathrm{Hb}$ ) Content, Packed Cell Volume (PCV) and Erythrocyte Sedimentation Rate (ESR)

\section{Total Erythrocyte Count (TEC)}

Thomas red blood cell pipette was used for Total erythrocyte count (TEC). The pipette was filled upto 0.5 mark with blood and diluting fluid (Hayem's solution) was then drawn till it reached the 101 mark. The contents were thoroughly mixed for 2 minutes. The dilution of the contents was 1:200. The counting chamber and cover slip were cleaned and dried properly. The cover slip was placed on the chamber and cover slip were cleaned and dried properly. The cover slip was placed on the chamber in proper position. The content of the pipette was again shaken and 2 or 3 drops of the fluid were expelled. The chamber was then filled with the contents so that the fluid was flown under the cover slip by capillary action. The ruled area at the chamber was filled completely, taking care that excess did not run into the troughs and no air bubble appeared under the cover slip. The counting chamber was then placed under microscope and examined first with low power objectives (10x) to ensure that there was an even distribution of the cells. The cells were then counted with the aid of high power objectives (100x). The central squares of the counting chamber were counted in the far corner and one central square of the chamber. The counting and calculation of red blood cells were performed as per methods indicated by Coffin (1955). The number of RBC was calculated as follows: Number of $\mathrm{RBC}=$ No. of cell counted $\times 10,000$ and the result was expressed in million/cu.mm.

\section{Determination of Hemoglobin (gm \%)}

The hemoglobin estimation was performed by the acid Haematin method with the Hellige Hemometer (Coffin, 1955). Hydrochloric acid (N/10) solution was taken in the special graduated tube upto its 20 mark. The special Sahli pipette was filled with well mixed oxalated blood upto 20 mark and blood on the side of the pipette was wiped out by cotton. The content of the Sahli pipette was expelled into the special graduated diluting tube and thoroughly mixed. The tube was then allowed to stand for 10 minutes for development of acid haematin. Distilled water was then added drop by drop and each time mixed with the help of stirring rod until the colour of the solution matched with the standard colour of the comparator. The result was read as per method described by (Coffin, 1955).

\section{Packed cell volume (PCV)}

The PCV was determined as per method described by (Coffin, 1955). The wintrobe haematocrit tube was filled up with well-mixed blood by special loading pipette upto 10 marks. Then the tube was centrifuged at 3,000 rpm for half an hour and reading was taken.

\section{Determination of Erythrocyte Sedimentation Rate (ESR)}

The collected blood sample was filled with the special loading pipette slightly above the ' 0 ' $\mathrm{mm}$ mark or ' 10 ' mark. The tip of the pipette was inserted to the bottom of the haematocrit tube and the blood was expelled by the pressure on the rubber bulb, withdrawn the pipette as the tube filled. Each tube was then placed in the special rack being certain that they were vertical. The tube was allowed to remain in the support without disturbance for an hour. The ESR value was determined as per methods describe by (Coffin, 1955).

\section{Statistical analysis}

Data obtained form the experiment were analyzed statistically using Student ' $t$ ' test. 


\section{Results and Discussion}

A research work was conducted to evaluate the anthelmintic activity and certain blood parameters of Neem (spray) and Ivomec ${ }^{\circledR}$ Ivermectin in comparison with the control group. In Group B, Neem at $15 \%$ spray was found to be $68 \%$ effective against tick infestation with the mean value of 12.20 \pm 1.2806 . Ticks were decreased within the selected area on 7 th, 14 th, $21 \mathrm{st}$ and $28^{\text {th }}$ day after the treatment on the other hand in control group A, the number of ticks increased gradually on 7th, 14th, 21st and 28th day of treatment. Group-C were treated with Ivermectin (subcutaneous formulation) at the dose rate of $200 \mu \mathrm{g} / \mathrm{kg}$ body weight showed $100 \%$ efficacy i.e. no ticks were found by physical examination on the 7th, 14th, 21st and 28th day of post treatment were as, the rate of tick infestation was constant in the calves of group A.

The hair coat of the infected calves (group B and C) was rough with discolored wool on day 0 . In group B and C, after treatment with Neem and Ivermectin, the hair coat started to become smooth and shiny gradually and on 28th day of treatment the hair coat of the treated calves were almost normal. The hair coat of the infected control group became more rough and discolored. The mean initial body weight of group B and C treated with Neem (15\%) and Ivermectin $(200 \mu \mathrm{g} / \mathrm{kg})$ were $18 \mathrm{~kg}$ and $16 \mathrm{~kg}$ on day 0 and on the 28th day of post treatment the mean values of body weight were $22 \mathrm{~kg}$ and $20 \mathrm{~kg}$, respectively. So body weight of calves increased significantly in treated groups on 28th day of treatment. In control group (A), body weight of calves was decreased upto $6.63 \%$ on 28th day of treatment. On the other hand, the body weight was increased in groups ( $B$ and $C$ ) to the extent of $3.11 \%-4.26 \%$. So body weight of calves increased significantly in treated groups on 28th day of treatment (Table 1).

Table 1. Effects of body weight $(\mathrm{kg})$ in calves

\begin{tabular}{|c|c|c|c|c|c|c|}
\hline Groups & Treatment & Pre-treatment & & Post- & atment & \\
\hline & & '0’ day & 7th day & 14th day & 21st day & 28th day \\
\hline A & Control & $18.388 \pm 0.167$ & $\begin{array}{c}18.242 \pm 0.162 \\
(0.80 \%)\end{array}$ & $\begin{array}{c}17.52 \pm 0.193 \\
(4.12 \%)\end{array}$ & $\begin{array}{c}17.242 \pm 0.103 \\
(1.61 \%)\end{array}$ & $\begin{array}{c}16.17 \pm 0.173 \\
(6.63 \%) b\end{array}$ \\
\hline B & Neem & $18.488 \pm 0.087$ & $\begin{array}{c}19.414 \pm 0.144 \\
(4.77 \%)\end{array}$ & $\begin{array}{c}19.632 \pm 0.115^{\star *} \\
(1.11 \%)\end{array}$ & $\begin{array}{c}19.524 \pm 0.201^{\star *} \\
(0.55 \%)\end{array}$ & $\begin{array}{c}21.80 \pm 0.80^{* \star} \\
(4.26 \%) \mathrm{a}\end{array}$ \\
\hline C & Ivermectin & $16.01 \pm 0.28$ & $\begin{array}{c}18.52 \pm 0.113 \\
(0.54 \%)\end{array}$ & $\begin{array}{c}19.184 \pm 0.110^{* *} \\
(3.46 \%)\end{array}$ & $\begin{array}{c}19.59 \pm 0.165^{*} \\
(2.07 \%)\end{array}$ & $\begin{array}{c}20.218 \pm 0.082 \\
(3.11 \%) \mathrm{a} \\
\end{array}$ \\
\hline
\end{tabular}

Values given above are mean \pm SE of 5 calves, * Significantly increased $(P<0.05)$, ** Significantly increased $(P<0.01)$

$(\% a)=$ Percent of increased $a,(\% b)=$ Percent of decreased $b$.

In control group (A), TEC values was decreased up to $2.45 \%$ on 28th day of treatment. On the other hand, the TEC values were increased in neem and ivermectin case of patent drugs treated groups (B and C) to the extent of $5.20 \%-9.25 \%$ (Table 2). So TEC values were increased significantly in treated groups on 28th day of treatment.

Table 2. Effects of ivermectin injectable formulation (Ivomec ${ }^{\circledR}$ ) and neem leaves on TEC (million/cu. $\mathrm{mm}$ ) in calves

\begin{tabular}{|c|l|l|c|c|c|c|}
\hline Groups & Treatment & Pre-treatment & \multicolumn{4}{|c|}{ Post-treatment } \\
\hline & & '0' day & 7th day & 14th day & 21st day & 28 th day \\
\hline A & Control & $7.16 \pm 0.108$ & $6.72 \pm 0.116$ & $6.46 \pm 0.150$ & $6.38 \pm 0.13$ & $6.54 \pm 0.154$ \\
& & & $(6.55)$ & $(4.02)$ & $(1.25)$ & $(2.45) \mathrm{b}$ \\
\hline B & Ivermectin & $6.8 \pm 0.084$ & $8.32 \pm 0.128^{\star \star}$ & $9.046 \pm 0.072^{\star \star}$ & $10.364 \pm 0.162^{\star}$ & $\begin{array}{c}11.42 \pm 0.169^{\star} \\
(12.72)\end{array}$ \\
& & & $(18.27)$ & $(8.03)$ & $(9.25) \mathrm{a}$ \\
\hline C & Neem & $6.47 \pm 0.156$ & $7.476 \pm 0.074$ & $8.91 \pm 0.213^{\star \star}$ & $10.068 \pm 0.078$ & $10.62 \pm 0.186^{\star \star}$ \\
& & & $(13.46)$ & $(16.09)$ & $(11.50)$ & $(5.20) \mathrm{a}$ \\
\hline
\end{tabular}

Values given above are mean \pm SE of 5 calves, * Significantly increased $(P<0.05)$, ** Significantly increased $(P<0.01)$

$(\% \mathrm{a})=$ Percent of increased $\mathrm{a}(\% \mathrm{~b})=$ Percent of decreased $\mathrm{b}$. 
In control group $(A)$, hemoglobin content was decreased upto $4.52 \%$ on 28 th day of treatment. On the other hand, the hemoglobin contents were increased in treated groups B and $C$ to the extent of $1.10 \%-3.02 \%$, respectively. So hemoglobin content was increased significantly in treated groups on 28th day of treatment (Table 2). In control group (A), PCV (\%) values was decreased upto $14.07 \%$ on 28th day of treatment. On the other hand, the PCV (\%) values were increased in all treated groups (B and $\mathrm{C}$ ) to the extent of $1.11 \%-1.45 \%$ (Table 3). In control group (A), ESR (mm/1st hr) values was increased upto 5.19 on 28th day of treatment. On the other hand, the ESR ( $\mathrm{mm} / 1 \mathrm{st} \mathrm{hr}$ ) values were decreased in all treated groups of $B$ and $C$ significantly $(P<0.001)($ Table 4$)$.

Table 3. Effects of ivermectin injectable formulation (Ivomec ${ }^{\circledR}$ ) and neem leaves on Hemoglobin $\mathrm{Hb}$ content (gm \%) in calves

\begin{tabular}{|c|l|c|c|c|c|c|}
\hline Groups & Treatment & Pre-treatment & \multicolumn{4}{|c|}{ Post-treatment } \\
\hline & & '0' day & 7th day & 14th day & 21st day & 28 th day \\
\hline A & Control & $6.58 \pm 0.420$ & $7.082 \pm 0.197$ & $6.62 \pm 0.180$ & $6.88 \pm 0.193$ & $6.59 \pm 0.168$ \\
& & & $(6.98)$ & $(6.88)$ & $(3.80)$ & $(4.52)$ \\
\hline B & Ivermectin & $6.46 \pm 0.144$ & $7.32 \pm 0.097^{\star \star}$ & $7.56 \pm 0.150^{\star \star}$ & $8.34 \pm 0.129^{\star}$ & $8.6 \pm 0.195^{\star}$ \\
& & & $(11.75)$ & $(3.17)$ & $(9.35)$ & $(3.02) \mathrm{a}$ \\
\hline C & Neem & $7.14 \pm 0.117$ & $7.38 \pm 0.116^{\star *}$ & $7.66 \pm 0.108^{\star *}$ & $8.60 \pm 0.145^{\star *}$ & $8.7^{\star *} \pm 0.114$ \\
& & & $(3.25)$ & $(3.66)$ & $(10.97)$ & $(1.10) \mathrm{a}$ \\
\hline
\end{tabular}

Values given above are mean \pm SE of 5 calves, * Significantly increased $(P<0.05)$, ** Significantly increased $(P<0.01)$

Table 4. Effects of ivermectin injectable formulation (Ivomec ${ }^{\circledR}$ ) and neem leaves on Packed cell volume (PCV) $(\%)$ values in calves

\begin{tabular}{|c|l|c|c|c|c|c|}
\hline Groups & Treatment & Pre-treatment & \multicolumn{4}{|c|}{ Post-treatment } \\
\hline & & '0' day & 7th day & 14th day & 21st day & 28 th day \\
\hline A & Control & $28.99 \pm 0.909$ & $29.63 \pm 0.259$ & $29.2 \pm 0.251$ & $26.44 \pm 0.267$ & $23.18 \pm 0.295$ \\
& & & $(2.17)$ & $(1.49)$ & $(10.44)$ & $(14.07)$ \\
\hline B & Ivermectin & $29.75 \pm 0.307$ & $29.58 \pm 0.229^{\star \star}$ & $29.49 \pm 0.159^{\star \star}$ & $30.69 \pm 0.433^{\star \star}$ & $30.36 \pm 0.469^{\star \star}$ \\
& & & $(0.57)$ & $(0.31)$ & $(3.93)$ & $(1.11)$ \\
\hline C & Neem & $28.41 \pm 0.349$ & $28.50 \pm 0.318^{\star \star}$ & $28.892 \pm 0.173^{\star \star}$ & $29.82 \pm 0.887$ & $29.39 \pm 0.381$ \\
& & & $(0.34)$ & $(1.33)$ & $(3.11)$ & $(1.45)$ \\
\hline
\end{tabular}

Values given above are mean \pm SE of 5 calves, * Significantly increased $(P<0.05)$, ** Significantly increased $(P<0.01)$

Table 5. Effects of ivermectin injectable formulation (Ivomec ${ }^{\circledR)}$ and neem leaves on Erythrocyte sedimentation rate (ESR $\mathrm{mm} / 1 \mathrm{st} \mathrm{hr}$ )

\begin{tabular}{|c|l|c|c|c|c|c|}
\hline Groups & Treatment & Pre-treatment & \multicolumn{4}{|c|}{ Post-treatment } \\
\hline & & '0’ day & 7th day & 14th day & 21st day & 28 th day \\
\hline A & Control & $0.944 \pm 0.019$ & $1.034 \pm 0.012$ & $1.404 \pm 0.017$ & $1.828 \pm 0.026$ & $1.928 \pm 0.033$ \\
& & & $(9.28)$ & $(26.35)$ & $(23.19)$ & $(5.19) \mathrm{a}$ \\
\hline B & Ivermectin & $0.146 \pm 0.010$ & $0.11 \pm 0.009$ & $0.0916 \pm 0.021^{\star \star}$ & $0.083 \pm 0.013^{\star}$ & $0.030 \pm 0.007^{\star \star}$ \\
& & & $(30.91)$ & $(20.09)$ & $(10.36)$ & $(76.67) \mathrm{b}$ \\
\hline C & Neem & $0.118 \pm 0.011$ & $0.0854 \pm 0.014$ & $0.060 \pm 0.004^{\star \star}$ & $0.050 \pm 0.007$ & $0.036 \pm 0.011^{\star \star}$ \\
& & & $(41.69)$ & $(42.33)$ & $(20.00)$ & $(38.89) \mathrm{b}$ \\
\hline
\end{tabular}

Values given above are mean $\pm S E$ of 5 calves, * Significantly increased $(P<0.05)$, ** Significantly increased $(P<0.01)$

$(\% a)=$ Percent of increased $a,(\% b)=$ Percent of decreased $b$.

The present findings supports the earlier observation of Ninkov and Savin (1986), Nettleton, and Beekett, (1976) and Sangwan et al.(1995) who reported 90\% to 100\% efficacy of ivermectin against tick infestation in calves. It was seen that no ectoparasites were present on body of animal after 7th day to the end the experiment (28th day post treatment). The hematological changes in calves affected with the ectoparasite were determined at pre and post treatment period dosed with Neem and Ivermectin. The mean value of haemogolobin was decreased in the ectoparasites affected calves (control group). The results are in agreement with the reports of Nettleton and Beekett (1976) and Anosa (1977). In the present study significant changes in $\mathrm{Hb}, \mathrm{gm} \%$ and $\mathrm{PCV} \%$ were observed in the treated group of calves and this might be due to expulsion of blood sucking and other parasites and ectoparasites from the body. The significant reduction in the sedimentation rate of erythrocytes in successfully treated group was observed and this may be due to recovery from inflammation in 
ectoparasites, which was produced by ectoparasites. about the changes of $\mathrm{Hb}, \mathrm{PCV}$ and ESR in the Ivermectin and Neem treated group. Anil-Kumar and Joshi (1992), found increase on $\mathrm{Hb}$ gm\% level in Ivermectin treated calves.

\section{References}

Anil, K. and Joshi, B.P. 1992. Anthelmintic efficacy of ivermectin against naturally occurring gastrointestinal nematodes of sheep. Indian VeterinaryJournal, 69: 935-937.

Anosa, V.O. 1977. Hematological observations on helminthiasis caused by Haemonchus contortus in Nigerian dwarf sheep. Bulletin of Tropical Animal Health and Production, Africa, 9: 11-17.

Chungsamarnyart, N. and Jansawan, W. 1991. Effect of Tamarindus indicus L. against the Boophilus microplus. Kasetsart J. Nat. Sci. 35: 34-39.

Coffin, D.L. 1955. Manual of Veterinary Clinical Pathology. Third Ed. Coinstock Publishing Associates. Inc. Ithaca New York, 116-157.

Dutta, P.K. and Hazarika, R.N. 1976. Chemotherapy of Stephanofilarial dermafitis in bovines. Indian Veterinary Journal, 53: 221-224.

Hannan, A.S.M.A., Mostofa, M., Haque, M.A. and Alim, M.A. 2001. Efficacy of Ivomec ${ }^{\circledR}$ pour on against gastrointestinal nematodes, lice and ticks in goats. Bangl. Vet. J. 18: 95-98.

Mannan, M.A., Rafiq, K., Mostofa, M. and Hasan, Q. 1997. Comparative efficacy of Ivermectin Neguvon and Neem-tobacco Herbal Preparations 106 against naturally occurring humpsore lesions in cattle. Bangl. Vet. J. 31: 119-122.

Mostofa, M. 1983. Efficacy of some indigenous medicinal plants against gastrointestinal nematodiasis in cattle and their comparative activity with that of Nemafax. M. SC (vet. Sc) Thesis, Dept of Pharmacology, BAU. Mymensingh.

Nath, K., Rajagopal and Garg, A.K. 1983. Water washed Neem seed kernel cake as a cattle feed. J. Agril. Sci. 101: 323-326.

Ninkov, D.H. and Savin, W. 1986. The comparative field efficacy of two anthelmintic topical pour on formulation in cattle. AgriPractice, 17:28-31.

Nettleton, P. and Beekett, P. 1976. Haematology of indigenous goat in Swaziland. Bulletin of Tropical Animal Health and Production Africa, 8:60-61.

Pedroso P.D., Moya B.G.E., Borja, G.E.M., Paiva, D. and Pedroso, D.E. 1994. Ivermectin for the control of Sarcopromusca pruna (Shannon and

Sangwan, R.P., Langholef, W.K., Cramer, L.G. and Eagleson, J.S. 1995. An ivermectin tablet for sheep; efficacy against gastrointestinal nematodes and a bioavilability comparison with a liquid ivermectin formulation. Veterinary Parasitology. 60: 297-302. 